\title{
O yôm YHWH, expressão e temática no corpus dos Doze Profetas ( $1^{a}$ Parte)
}

\author{
Leonardo Agostini Fernandes
}

\section{Introdução}

A história, na concepção bíblica, não é algo estático ou cíclico, mas uma realidade que conhece progressão e abertura para o dado novo acontecer. A razão disto reside no fato de que a história está marcada pela presença e ação de YHWH, que nela se manifesta no decorrer do tempo, dos dias e em momentos que diríamos privilegiados ${ }^{1}$.

O tempo também, segundo a concepção bíblica, não é uma res abstracta, um qualquer coisa de teórico e a priori para dar suporte aos fatos, mas é um elemento que está intrinsecamente ligado a um acontecimento, de modo que cada tempo tem o seu acontecimento e, por sua vez, cada acontecimento tem o seu devido tempo ${ }^{2}$.

\footnotetext{
${ }^{1}$ Cf. W. EICHRODT, Teología del Antiguo Testamento, I, Dios y Pueblo, Madrid, 1975, 38-39. 346-349.

${ }^{2}$ Em hebraico não existem as categorias temporais de passado, presente e futuro, mas nos textos se verificam as distinções entre passado e presente (cf. Dt 5,1-3; 8,19; 9,7-9), entre presente e futuro (cf. Dt 7,9-11) e entre passado, presente e futuro (cf. Dt 29,28). Ao lado disto, advérbios e partículas com o infinito construto podem expressar estas categorias temporais (cf. W. I. REHFELD, Tempo e Religião. A experiência do homem bíblico, São Paulo, 1988, 5152.129.153). Qoh 3,1-8 confirma isto denotando ainda que a vida humana não está enraizada só no evento que acontece no seu específico instante, mas na concatenação e no nexo que cria a possibilidade de um novo evento e do seu instante (cf. A.-M. PELLETIER, La Bíblia e l'Occidente. Letture bibliche alle sorgenti della cultura occidentale, Bologna 1999, 248-250).
} 
YHWH é o Senhor do tempo não só porque Ele o criou em um constante e perfeito alternar-se de "dia" e de "noite", mas porque YHWH, que é o Primeiro e o Último (cf. Is 44,20; 48,12; Ap 1,17; 22,13), continuamente sustenta e intervém no tempo com a sua presença e ação providente. Esta intervenção divina revela que a história possui um escopo e que ela se encaminha para um fim que corresponde ao desígnio absoluto de YHWH.

A respeito deste momento decisivo para a história, os fiéis cristãos esperam, segundo a revelação bíblica, a chegada dos novos céus e da nova terra, nos quais habitará plenamente a justiça (cf. Is 51,16 ; $2 \mathrm{Pd} 3,13$ ) e onde não existirá mais sombra de mal, de sofrimento e de morte.

$\mathrm{O}$ anúncio bíblico-profético de punição ou de salvação sustenta que bons e maus receberão, no fim dos tempos e da história, a justa recompensa por suas ações. Isto seria o núcleo da temática bíblico-teológica sobre a escatologia e sobre a idéia que nós temos da parusia.

Na história, então, encerra-se um mistério, porque ela está vinculada e mantida por Aquele que É , que nela se revela e a conduz em virtude do seu desígnio salvífico. Sendo assim, todos os fatos da história devem ser valorizados por uma visão de fé que os interprete de forma teofânica e teocêntrica.

Os homens, portanto, não devem viver na história de maneira passiva, mas ativa, pois são chamados a protagonizar, como verdadeiros colaboradores de YHWH, a condução do âmbito natural da vida no desenrolar da história.

Destaque, neste sentido, pode ser dado aos profetas de Israel que são e agem, na história do seu povo, como luzeiros, isto é, como verdadeiros sinais que buscam compreendê-la e traduzi-la, ajudando o povo a tomar consciência da sua própria existência e finalidade no plano salvífico de $\mathrm{YHWH}^{3}$.

Uma fórmula usada por alguns profetas para denotar uma qualitativa intervenção temporal de YHWH na história encontra-se na expressão $\mathbf{I}^{4}$. Esta expressão, porém, dificilmente poderia ser explicada por um estudo exegético-teológico que só levasse em conta os seus dois termos ${ }^{5}$.

${ }^{3}$ Cf. A. GELIN, “Jours de Yahvé et Jour de Yahvé", LetV 11 (1953) 39-40.
${ }^{4}$ A partir daqui, utilizaremos a transliteração yôm YHWH.
${ }^{5}$ As passagens em que ocorre yôm no estado construto são numerosas, quase sempre determi-
nando o sentido temporal no qual acontece um fato. O estado construto, às vezes, tem valor
qualitativo ou, de forma mais rara, de finalidade, caso se trate de eventos esperados para o futu-
ro. Em menor número são os casos em que o sentido é qualitativo e o nome, neste caso, poderia
ser substituído por um adjetivo. Para uma estatística sobre a freqüência do termo yôm no Antigo
Testamento, cf. E. JENNI, "םי",, in E. JENNI - C. WESTERMANN, Diccionario Teologico
Manual del Antiguo Testamento, I, Madrid 1978, 975-1000. C. CARNITI ("L'espressione 'il
Giorno di Yhwh': origine ed evoluzione semantica", BeO 12 [1970] 11-25; P. A. VERHOEF,
"םI", in W. A. VAN GEMEREN, The New International Dictionary of Old Testament Theology
and Exegesis, Michigan, 1997, n. 3427, 419-424. Um estudo neste sentido foi feito por D. I. 
O yôm YHWH, portanto, encontra-se inserido no quadro desta fé revelada e da questão sobre a escatologia bíblica. É uma expressão teológica importante que diz respeito à ação da justiça de $\mathrm{YHWH}$ proclamada tanto no Antigo Testamento como no Novo Testamento, que valorizou e retomou a temática para evidenciar o dia da manifestação gloriosa do Filho do Homem (cf. Lc 17,24.30; 1Cor 1,8; 5,5; 1Ts 5,2; 2Pd 3,10; Ap 16,14).

\section{Status Quaestionis}

A expressão yôm YHWH está testemunhada em alguns escritos proféticos, mas o maior número das ocorrências explícitas encontra-se no corpus do $\delta \omega ́ \delta \epsilon \kappa \alpha \pi \rho \circ \phi \eta \tau \omega \nu^{6}$. Nos últimos cem anos ${ }^{7}$, os estudos bíblicos têm se ocupado com o yôm YHWH em dois sentidos:

a) o seu Sitz im Leben, buscando individuar e entender os elementos que dizem respeito à sua natureza, origem e valor escatológico;

b) o seu papel nos escritos proféticos, buscando determinar a importância da expressão, em particular, nos Doze Profetas.

ROSENBOIM, «Is יוום ה' (The Day of the Lord) A Term in Biblical Language?», Bib 87 (2006) 395-401.

${ }^{6}$ A partir daqui, utilizaremos a transliteração Dodekapropheton.

${ }^{7}$ Cf. H. GRESSMANN, Ursprünge der israelitisch-jüdischen Escatologie, Göttingen, 1905; P. HAUPT, "The Prototype of the Dies Irae", JBL 38 (1919) 142-151; A. GELIN, "Jours de Yahvé et Jour de Yahvé", 39-52; G. von RAD, "The Origin of the Concept of the Day of Yahweh's", JSSt 4 (1959) 97-108; J. HÉLÉWA, "L'Origine du Concept Prophétique du 'Jour de Yahvé",' ECarm 14 (1964) 3-36; K. D. SCHUNCK, "Strukturlinien in der Entwicklung der Vorstellung von 'Tag JAHWES", VT 14 (1964) 319-330; F. C. FENSHAM, "A Possible Origin of the Concept of the Day of the Lord", OTWSA 5-6 (1966) 90-97; M. WEISS, "The Origin of the 'Day of the Lord' Reconsidered", HUCA 37 (1966) 29-71; J. P. COMISKEY, "The Day of the Yahweh - divine judgment unto wrath or mercy", BiTod 32 (1967) 2214-2220; C. CARNITI, "L'espressione 'il Giorno di Yhwh'..."; A. J. EVERSON, "The Days of YAHWEH", JBL 93 (1974) 329-337; J. GRAY, "The Day of Yahweh in Cultic Experience and Eschatological Prospect", SEA 39 (1974) 5-37; Y. HOFFMANN, "The Day of the Lord as Concept and a Term in Prophetic Literature", ZAW 93 (1981) 37-50; G. FOHRER, "Der Tag Jhwhs", ErIs 16 (1982) 43-50; K. JEPPESEN, "The Day of the Yahweh in Mowinckel's Conception Reviewed", SJOT 2 (1988) 42-55; H. SPIECKERMANN, "Dies Irae: Der Alttestamentliche Befund und Seine Vorgeschichte", VT 39 (1989) 194-208; A. G. KING, "The Day of the Lord in Zephaniah", BS 152 (1995) 16-32; M. CIMOSA, "Il giorno del Signore e l'escatologia nell'Antico Testamento", in VV.AA, Dizionario di Spiritualità Biblico-Patristica, vol. 16: Escatologia, Roma, 1997, 2062; R. RENDTORFF, "Alas for the Day! The 'Day of the Lord' in the Book the Twelve", in T. LINAFELT - T. K. BEAL, God in the Fray. A Tribute to Walter Bruggemann, Minneapolis, 1998, 186-197; J. D. NOGALSKI, "The Day(s) of YHWH in the Book of the Twelve", SBL.SP, Atlanta, 1999, 617-642; D. I. ROSENBOIM, «Is 'יוֹם ה' (The Day of the Lord) A Term in Biblical Language?», 395-401. 
Quanto ao primeiro sentido, para a história da exegese, predominam três nomes e suas respectivas teses, que ainda hoje são reconhecidas como sendo as principais ${ }^{8}$ :

a) H. Gressmann, inspirando-se na mitologia babilônica, onde uma catástrofe final ocasionaria o surgimento de um novo mundo, colocou o yôm YHWH no âmbito da escatologia profética ${ }^{9}$;

b) S. Mowinckel, a partir da festa mesopotâmica do ano novo, aplicando-a à festa da entronização de $\mathrm{YHWH}^{10}$, propôs o yôm YHWH com sentido cultual e escatológico;

c) G. von Rad, reconhecendo que YHWH combatia nas batalhas a favor do seu povo ante seus inimigos, associou o yôm YHWH com a tradição da «guerra santa»" 11 .

Quanto ao segundo sentido, os estudos surgidos nos últimos trinta anos se esforçam por encontrar, utilizando a índole temática do yôm YHWH, um indício plausível que seja capaz de demonstrar que o Dodekapropheton foi idealizado para ser um «único livro». A unidade deste corpus estaria assegurada pela ordem canônica dos escritos na Bíblia hebraica $(\mathrm{BH})$, através de termos chaves e temas condutores. O yôm YHWH, como expressão e temática, é admitido como sendo um dos principais ${ }^{12}$.

\footnotetext{
${ }^{8}$ Cf. H. SIMIAN-YOFRE, Amós, 120. Destas três teorias foram desenvolvidas outras, que trouxeram críticas, ampliações e alterações, mas a ligação com as três permaneceu. Para uma avaliação mais atualizada sobre a evolução do argumento, cf. A. J. EVERSON, The Day of Yahweh, 2-44; H.-M. BARSTAD, The Religious Polemics of Amos. Studies in the Preaching of Am 2,7b-8; 4,1-13; 5,1-27; 6,4-7; 8,14 (VT.S 34), Leiden 1984, 89-103.

${ }^{9}$ Cf. H. GRESMANN, Der Ursprung, 147.

${ }^{10}$ Cf. S. MOWINCKEL, Psalmenstudien, II. Das Thronbesteigerungsfest Jawäs und der Ursprung des Eschatologie, Kristiania 1922, 229-230; He that Cometh, Oxford 1956, 132.

${ }^{11}$ Cf. G. von RAD, «The Origin», 97-108; Teologia dell'Antico Testamento, Paideia, Brescia 1974, 146-152.

${ }^{12}$ A edição de P. L. Redditt e A. Schart (Thematic Threads in the Book of the Twelve) e de J. D. Nogalski (Int 61/2 [2007] 115-204) oferecem numerosos artigos a respeito desta linha de pesquisa. Todavia, deve-se manter a conviç̧ão de que a mensagem e um suposto significado canônico para o Dodekapropheton não cancelaria a mensagem teológica e o significado individual que cada um destes escritos proféticos possuem e representa neste corpus (cf. J. BARTON, «The Canonical Meaning», 59-73; M. L. S. SOUZA, O Livro de Miquéias no conjunto dos doze profetas. Estudo intertextual entre Mq 7,8-20 e os chamados pequenos profetas, (Diss/Doct PUC-RJ), Rio de Janeiro 2006, 79-89; M. L. C. LIMA, «Doze Profetas ou Livro dos Doze?» At. Teo 11 (2007), 214-216; F. BARGELLINI, «Il ruolo canonico di Gioele, Abdia e Giona. Elementi per uma lettura unitária dei XII Profeti Minori», RivB 55/2 (2007)145-163; L. A. FERNANDES, $O$ yôm YHWH em Jl 2,1-11. Um estudo temático em Joel e seu influxo no Dodekapropheton, (Diss/Doct PUG-Roma), Roma 2008, 1-10.61-69).
} 
O interesse dos que se dedicam ao estudo unitário do Dodekapropheton submete os textos usando uma abordagem tanto diacrônica ${ }^{13}$ como sincrônica ${ }^{14}$. Os resultados até agora obtidos, porém, não mostram claramente, como a temática do yôm YHWH possa ser considerada um motivo teológico apto a levar para os textos, onde a expressão ocorre, um conjunto de reflexões sobre outras temáticas que pertencem ao patrimônio da fé veterotestamentária: a sublimidade de Sião; a justiça divina; a ideologia da retribuição; a lei do talião etc.

A expressão, como tal, encontra-se dezesseis vezes na BH e está presente em perícopes de épocas diversas ${ }^{15}$. Supõe-se que o texto mais antigo, em referência ao yôm YHWH, seja o de Am 5,18-20. Contudo, os elementos e características que nele se encontram, como veremos mais adiante, não são suficientes para entendermos cabalmente o que venha a ser o yôm $\mathrm{YHWH}^{16}$.

Não é fácil entrever e tampouco dizer, com profundidade e clareza, o que profeta Amós sabia a respeito do yôm YHWH e/ou se já existia, nos seus dias ou num tempo anterior à sua pregação, uma idéia em circulação a respeito desta temática e qual a carga teológica nela inserida ${ }^{17}$.

É possível dizer, previamente, que Amós enfatizou e deu a entender que este dia seria de trevas e escuridão. O profeta parece-nos inverter, senão corrigir, uma possível concepção vigente e predominante sobre o favor divino que o povo estaria esperando que fosse acontecer neste dia ${ }^{18}$.

${ }^{13}$ Cf. A. SCHART, Die Entstehung des Zwölfprophetenbuches, BZAW 260, Berlin - New York 1998; M. BECK, Der „Tag YHWHs“ im Dodekapropheton: Studien im Spannungsfeld von Traditions - und Redaktiongeschicht, BZAW 356, Berlin - New York 2005; P. G. SCHWESIG, Die Rolle der Tag-JHWHs-Dichtungen im Dodekapropheton, BZAW 366, Berlin - New York 2006.

${ }^{14}$ Cf. R. RENDTORFF, «How to read the Book of the Twelve as a Theological Unity», in SBL.SP 36 (1997) 420-432; «Alas for the Days!», 186-197; The Canonical Hebrew Bible: A Theology of the Old Testament, Leiden 2005, 264-314; J. D. NOGALSKI, «The Day(s) of YHWH», 617-642. Para uma visão de conjunto sobre a problemática até o limiar que fez surgir essas novas pesquisas, cf. M. S. MOORE, «Yahweh's Day», 193-206.

${ }^{15}$ Cf. A. S. KAPELRUD, The Message of the Prophet Zephaniah. Morphology and Ideas. Oslo 1975, 80-87.

${ }^{16}$ Cf. L. A. FERNANDES, O yôm YHWH em $J l$ 2,1-11, 159-161.245-247.

${ }^{17}$ Sobre este dado, os críticos se posicionam basicamente em dois sentidos. Há os que sustentam que Amós é o responsável pela expressão: A. GELIN, "Jours de Yahvé et Jour de Yahvé", 44; C. CARNITI, "L'espressione 'il Giorno di Yhwh'...", 11. E há os que sustentam que Amós fala de uma realidade já familiarizada aos ouvintes: H. GRESSMANN, Der Ursprung der jüdisch-israelitischen Eschatologie, 147; J. P. COMISKEY, "The Day of the Yahweh - divine judgment unto wrath or mercy", 2214; G. FOHRER, "Der Tag Jhwhs", 43-50. Que Amós tenha sido o primeiro a usar tal expressão é um parecer quase unânime entre os dois grupos.

${ }^{18}$ Nos dias de Amós, tem-se a idéia de que o reino do Norte vivia um tempo de prosperidade, vislumbrando um futuro promissor e tranqüilo, visto que a dinastia de Jehú, ungido por um discípulo de Eliseu (cf. 2Rs 9; 13; 14,23-29; 15,8-12) estava sólida e várias vitórias militares a tinham estabelecido firmemente, de modo a fazer pensar que o yôm YHWH seria um dia favorável para aumentar as fronteiras, prosperar materialmente e instaurar uma paz soberana. 
Esta idéia negativa, veiculada por Amós, teria sido (re)utilizada ou (re)interpretada por outros profetas que continuaram afirmando que o yôm YHWH seria um dia de trevas e escuridão, e que, concomitante à sua vinda, se verificariam certos sinais de mutação nos elementos cósmicos (cf. Is 13,10; Ez 30,3; J1 2,2; 3,4; Sf 1,15).

O termo yôm unido a YHWH, é usado em dois tipos de construção:

1' (cf. Am 5,18.20; Is 13,6.9; Ez 13,5; Sf 1,7.14ab; Ab 15; Ml 3,23; Jl 1,15; 2,1.11; 3,4; 4,14);

$2^{o}$ ) יוֹם לִיהוֹ referindo-se à atividade processual de YHWH (cf. Is 2,12; Ez 30,3) ${ }^{19}$.

Estas duas expressões aparecem construídas, geralmente, com os adjetivos qārôb ("próximo") e gādôl ("grande") acompanhados do verbo bôo ("ir, vir, entrar"). A ligação do yôm YHWH com o adjetivo qââô e com o verbo $b \hat{o}^{\text {, }}$, precedido de lifnê ("diante de", "na presença de") no particípio com o sentido temporal futuro ("está vindo"), indica este dia como um evento futuro, algo a se cumprir. Ao que parece, somente Ez 13,5 estaria descrevendo uma realidade já acontecida, que corresponderia à primeira deportação dos judeus ocorrida no ano 597 a.C. (cf. 2Rs 24,1416). Já a relação com o que está por vir pode ser confirmada pelo anúncio contido em Is 13,6 e J1 1,15 ${ }^{20}$.

Acredita-se que esta expressão foi usada pelos profetas para indicar um complexo de idéias e de imagens teológicas ${ }^{21}$. A hipótese mais seguida admite que no patrimônio das tradições populares de Israel encontrar-se-ia o conceito de um dia particular, chamado yôm YHWH, entendido como um dia em que YHWH se manifestaria na história a favor do seu povo, libertando-o de todos os seus inimigos ${ }^{22}$.

O passado de Israel conheceu tempos memoráveis, de modo que, em meio a situações difíceis e calamitosas, Israel, olhando e refletindo sobre a sua história, nela encontraria as inúmeras vitórias antigas, conseguidas graças à presença e à potente intervenção de YHWH.

Não se tem aqui uma simples idéia do retorno dos acontecimentos, como se fosse uma concepção cíclica do tempo, mas uma certeza que brota da fé sempre viva em YHWH que opera maravilhas no meio do seu povo.

Cf. A. GELIN, "Jours de Yahvé et Jour de Yahvé", 44; A. S. KAPELRUD, The Message of the Prophet Zephaniah, 81.

${ }^{19}$ Cf. L. A. FERNANDES, O yôm YHWH em Jl 2,1-11, 159-160.

${ }^{20}$ Cf. A. SPREAFICO, Sofonia, Genova 1991, 98. Alguns afirmam que o yôm YHWH poderia estar presente, também, na forma "hayyôm" ou "bayyôm hahû". Cf. J. P. COMISKEY, "The Day of Yahweh: divine judgment unto wrath or mercy", 2215; L. A. FERNANDES, $O$ yôm YHWH em Jl 2,1-11, 158-159.

${ }^{21}$ Cf. C. CARNITI, "L’espressione 'il Giorno di Yhwh'...”, 11.

${ }^{22}$ Cf. A. GELIN, "Jours de Yahvé et Jour de Yahvé”, 41-42. 
Isto teria feito surgir e alimentado a esperança em uma sempre nova ação de YHWH, que seria tanto maior e majestosa quanto maior fosse a necessidade salvífica que o momento exigisse ${ }^{23}$.

As pesquisas realizadas, na intenção de encontrar uma solução para a questão quanto à origem da expressão são várias e possíveis, mas, até hoje, elas não alcançaram e não ofereceram uma palavra satisfatória e final sobre tal problema ${ }^{24}$.

Duas questões se impõem em torno do yôm YHWH: Qual a origem da expressão? e em que consiste, realmente, este yôm $?^{25}$

Pelo parecer de A. Spreafico, as possíveis tentativas de solução quanto à origem de tal concepção podem ser apresentadas e resumidas da seguinte maneira:

1) religião mesopotâmica ou cananéia (hipótese de $\mathrm{H}$. Gressmann e $\mathrm{S}$. Mowinckel);

2) religião e tradições de Israel (hipótese de G. von Rad) ${ }^{26}$.

Quanto à segunda questão, é necessário perceber o sentido do yôm YHWH pelo uso da expressão nos oráculos proféticos. Assim, por exemplo, se o yôm YHWH é originário da tradição da "guerra santa», ele indicaria uma perspectiva positiva para Israel ou se, derivasse da concepção de aliança, diria respeito à aplicação da bênção ou da maldição divina ao seu povo (cf. Dt 28-30).

\footnotetext{
${ }^{23}$ De fato em Am 5,18 a impressão que se tem, é de uma esperança e expectativa sempre favoráveis: "um dia de luz". Os autores sagrados, contudo, teriam tomado tal tradição popular e a ela atribuíram um novo significado, onde o yôm YHWH não seria, como se esperava, um dia em que YHWH se manifestaria favoravelmente por Israel, mas seria um dia de punição de todos os malvados e infiéis, entre os quais os próprios filhos de Israel, que não permaneceram fiéis à aliança. Cf. G. VON RAD, "The Origin of the Concept of the Day of Yahweh's", 103-108; P. AUVRAY e X. L. DUFOUR, "Dia do Senhor", in X. L. DUFOUR, Vocabulário de Teologia Bíblica, Petrópolis 1992, 230-231. A. GELIN ("Jours de Yahweh et jour de Yahweh", 44) segue a mesma hipótese, mas sustenta que a sociedade hebraica do século VII a.C. estava marcada por uma situação de bem-estar e não por situações difíceis.

${ }^{24}$ Cf. F. C. FENSHAM, "A Possible Origin of the Concept of the Day of the Lord", 90-97; A. J. EVERSON ("The Days of YAHWEH", 329) afirma que a origem do yôm YHWH está em conexão com a questão da origem das tradições em Israel, de modo que os estudiosos têm se concentrado em torno da pergunta sobre a origem das tradições para que possam compreender corretamente o que vem a ser o yôm YHWH. Ele propõe que o yôm YHWH seja estudado a partir de cinco textos (cf. Lm 1-2; Ez 13,1-9; Jr 46,2-12; Is 22,1-14), por ele considerados como descritivos e interpretativos de fatos passados relacionados ao anúncio do yôm YHWH.

${ }^{25}$ A forma como os críticos tratam as duas questões nem sempre apresenta clareza e distinção. Tentaremos, para cada hipótese, oferecer uma linha de pensamento que proporcione entrever tanto a questão da origem, quanto do sentido da expressão.

${ }^{26}$ Cf. A. SPREAFICO, Sofonia, 99.
} 


\subsection{As principais hipóteses}

a) H. Gressmann ${ }^{27}$ possui o mérito de ser o primeiro exegeta a procurar uma solução científica para o problema da origem da escatologia profética no seu conjunto ${ }^{28}$. Ele, colocando o yôm YHWH no âmbito da escatologia profética, concebeu a sua origem não em Israel, mas nas antigas concepções mitológicas babilônicas, que falam de uma catástrofe final, que traria a destruição deste mundo para originar a aparição de um mundo novo.

Este estudioso interpretou a expressão yôm YHWH como um dia escatológico. A sua origem seria extra-bíblica e coincidiria com o surgimento da escatologia bíblica, da qual o yôm YHWH seria uma das suas formas.

Gressmann considerou, então, a origem da escatologia bíblica não em Israel, mas nas complexas mitologias do Antigo Oriente Próximo ${ }^{29}$. Israel, graças ao contato com a cultura assiro-babilônica, acolheu estas idéias mitológicas, desenvolvendo-as e transformando-as em concepções populares, como se percebe acentuada em Am 5,18-20.

Por este parecer, Amós não teria sido o primeiro a usar tal expressão. O profeta já a encontrara forjada e circulando vivamente na mentalidade de Israel. Amós apenas aplicou-a ao seu oráculo, dando-lhe uma interpretação que fosse capaz de interpelar e provocar a conversão dos interlocutores ${ }^{30}$.

\footnotetext{
${ }^{27}$ Cf. H. GRESSMANN, Der Ursprung, 147.
}

${ }^{28}$ Para um status quaestionis sobre o que se entende por escatologia bíblica e quais os critérios necessários para que um texto possa ser tido por escatológico, veja-se a tese doutoral de M. L. C. LIMA, Salvação entre Juizo, Conversão e Graça, 26-27.

${ }^{29}$ A opinião de H. Gressmann, contudo, foi criticada duramente e a conexão com a mitologia babilônica ainda permanece duvidosa (cf. L. CERNY, The Day of Yahwh and Some Relevant Problems, Prague, 1948, 38-40).

${ }^{30}$ Cf. J. HÉLÉWA, "L’Origine du Concept Prophétique du 'Jour de Yahvé", 4-6; J. P. COMISKEY, "The Day of Yahweh: divine judgment unto wrath or mercy", 2217; G. FOHRER, "Der Tag Jhwhs", 43-50. Segundo Fohrer, o texto mais antigo que fala explicitamente do yôm YHWH é Am 5,18-20. É evidente, para ele, que o profeta Amós, nesta passagem, faz uso de uma expectativa e esperança já conhecidas, e como parece, já divulgadas, interpretando-as num modo novo, típico da profecia, visto que haviam israelitas que desejavam o Dia da vinda de YHWH, como um algo favorável para todo o Israel. Deve ter-se tratado de uma expectativa de salvação, de forma que os ouvintes dos profetas consideravam-no como um argumento contra o anúncio de desgraças. Não esperavam a morte e a perdição, mas salvação - "luz" e "esplendor". Amós, porém, interpreta o yôm YHWH num sentido contrário e o inclui no seu anúncio de desgraça: o yôm YHWH não iria trazer salvação como os israelitas esperavam, mas desgraça terrível: "trevas" e "escuridão".

Esta interpretação não é defendida por C. CARNITI ("L'espressione 'il Giorno di Yhwh'...”, 15), pois é difícil que Amós estivesse se referindo a uma idéia já formada e difundida, que a retomasse e a transformasse segundo uma nova concepção ética da religião e que se servisse de imagens já conhecidas do povo, reapresentando-as com uma interpretação nova. Argumenta que o livro de Amós dá a perceber que a impressão de uma espera geral de Deus 
b) S. Mowinckel sustenta que a origem e a forma da escatologia bíblica devem ser buscadas no âmbito e ambiente cultual, mais precisamente na festa mesopotâmica que celebrava o ano novo. Esta festa, também de origem extra bíblica, passou para a história da religião de Israel, originando a festa da entronização de YHWH, como tempo da sua teofania ${ }^{31}$.

A aliança do Sinai em Ex 19 é citado como o início da prosperidade para o povo eleito ${ }^{32}$.

Este estudioso distingue dois dias de YHWH, que estariam em estreita simetria. O primeiro yôm YHWH é puramente cultual e não é outra coisa senão o próprio dia da festa de entronização de YHWH, com todas as realidades ideológicas e cultuais que ela contém ${ }^{33}$. O segundo yôm YHWH, derivado do primeiro, é escatológico e representa a projeção para o advir das realidades anualmente repetidas no drama cultual da festa de entronização ${ }^{34}$.

Mowinckel sustenta sua hipótese em virtude das expectativas ainda não concretizadas que o povo celebrou no dia da festa. Este as projeta para um futuro longínquo e distante, fazendo com que a concepção cúltica do yôm YHWH se tornasse também uma realidade escatológica ${ }^{35}$.

Assim, a perspectiva do yôm YHWH, esperado para um amanhã, faria perder a ligação do yôm com a festa da entronização para se tornar indicação do dia escatológico, isto é, de uma intervenção eficaz e definitiva de YHWH contra os inimigos do seu povo, trazendo a libertação das angústias, realizando a paz e instaurando condições favoráveis para o povo viver seguro ${ }^{36}$.

Esta dupla e simétrica significação do yôm YHWH, para Mowinckel, é a chave de toda a escatologia bíblica. Sobre isso, ele baseia toda a sua teoria

se contrasta com a presença de um povo estulto, confiante numa excessiva bondade do Senhor e pouco preocupado com uma sua intervenção (cf. Am 5,4-6.14; 6,1-3).

${ }^{31}$ Cf. S. MOWINCKEL, Psalmenstudien, II, 229. Todavia, a respeito desta festa, não existe vestígio nos textos legislativos nem antigos nem recentes, tampouco existe uma referência explícita ou uma descrição em outros textos. Os elementos interpretados como caracterizadores desta festa podem ser explicados de maneira diversa, compreendida a afirmação de alguns salmos régios: "YHWH tornou-se rei" (cf. Sl 47,9; 93,1; 96,10; 97,1; 99,1). Uma vez que se pôs em discussão a existência de tal festa da entronização de YHWH, a identificação do yôm YHWH com o dia desta festa ficaria insustentável (cf. J. P. COMISKEY, "The Day of Yahweh: divine judgment unto wrath or mercy", 2218; A. SPREAFICO, Sofonia, 100-101). Em contrapartida, para F. C. FENSHAM ("A Possible Origin of the Concept of the Day of the Lord", 90), mesmo considerando que não foi apresentada nenhuma prova concreta sobre a existência de tal festa, isto não eliminaria todos os argumentos de Mowinckel com relação a uma celebração cúltica festiva desta natureza em certos períodos da história de Israel.

${ }^{32}$ Cf. A. S. KAPELRUD, The Message of the Prophet Zephaniah, 83.

${ }^{33}$ Cf. S. MOWINCKEL, He that Cometh, Oxford, 1956, 132.

${ }^{34}$ Cf. S. MOWINCKEL, Psalmenstudien, II, 230.

${ }^{35}$ Cf. A. S. KAPELRUD, The Message of the Prophet Zephaniah, 83.

${ }^{36}$ Cf. A. J. EVERSON, "The Days of YAHWEH”, 329-330. 
concernente à origem e ao conteúdo da escatologia em Israel. Tal festa, «assimilada e assumida», passou a ter um caráter autenticamente israelita, de modo que o yôm YHWH, como uma pura emanação escatológica, passa a ter a sua origem em Israel e não em concepções extra-bíblicas ${ }^{37}$.

c) G. von Rad se opõe à hipótese de S. Mowinckel, julgando avançar na direção de uma possível solução para o problema quanto à origem do yôm YHWH. Para von Rad, esta origem é profética e a raiz desta temática se encontra na história religiosa de Israel, em particular na tradição em torno da «guerra santa» e não num âmbito extra-bíblico.

O yôm YHWH, para ele, nada teria a ver com a origem da escatologia, mas seria uma expectativa ligada àquela tradição. O yôm YHWH seria um evento onde YHWH se manifestaria para aniquilar todos os inimigos de Israel, que seriam derrotados mediante uma ação bélica potente de $\mathrm{YHWH}^{38}$.

Para sustentar sua teoria, G. von Rad rejeita tomar como base o texto de Am 5,18-20 como sendo o início de toda a sua investigação sobre a origem do yôm YHWH. Ele faz esta opção, porque Amós apresenta a intervenção de YHWH não a favor, mas contra Israel. A sua opção, na verdade, contradiz a idéia de uma «guerra santa» como base do yôm $\mathrm{YHWH}^{39}$.

G. von Rad prefere estudar e avaliar a questão da temática do yôm YHWH através da história das formas (Formgeschichte) e da história das tradições (Überlieferungsgeschichte), a fim de ver se esta expressão não estaria ligada a um gênero literário particular. Seu ponto de partida, então, são os textos de Is $13 ; 34 ; \mathrm{Ez} 7 ; 30 ; \mathrm{Jl} 2$. Por estes, ele sustenta que o yôm YHWH se liga à idéia da guerra que YHWH empreende a favor de seu povo e contra os seus inimigos ${ }^{40}$.

\footnotetext{
${ }^{37}$ Cf. J. HÉLÉWA, "L’Origine du Concept Prophétique du 'Jour de Yahvé’”, 6-9. A posição de $\mathrm{S}$. Mowinckel com relação à origem do yôm YHWH foi revisada por K. J. AARHUS, "The Day of YAHWEH in Mowinckel Conception Reviewed", SJOT 2 (1988) 42-55.

${ }^{38}$ Cf. G. VON RAD, Teologia dell'Antico Testamento, 146-152; "The Origin of the Concept of the Day of Yahweh's", 97-108; E. TESTA fala de um substrato cananeu do dia de YHWH, mas segue a hipótese de G. von Rad em seu tratado sobre Sofonias (cf. E. TESTA, "Sofonia", 293-296); A. J. EVERSON, "The Days of YAHWEH”, 329-330.

${ }^{39}$ Segundo alguns críticos, este é o ponto fraco da teoria de G. von Rad, no momento em que despreza o texto mais antigo de Am 5,18-20, que para ele não ajuda a responder quanto à questão da origem do yôm YHWH, o mesmo acontecendo com o texto Is 2,12-22. Agindo por exclusão, G. Von Rad elimina dois textos importantes da discussão em torno desta questão (cf. A. S. KAPELRUD, The Message of the Prophet Zephaniah, 81-84).

${ }^{40}$ Cf. G. Von RAD, Teologia do Antigo Testamento, II, 120-121.
} 
Tal concepção inserir-se-ia no conjunto da antiga tradição da «guerra santa» e teria sua origem no anúncio profético de salvação e não no anúncio de desgraça, como aparece exemplificado em Am 5,18-20 ${ }^{41}$.

Portanto, o yôm YHWH não pertenceria, na sua origem, nem à escatologia extra-bíblica (contrário a $\mathrm{H}$. Gressmann) nem ao culto (contrário a $\mathrm{S}$. Mowinckel), mas pertenceria à expectativa profética que tradicionalmente se posicionou favorável à conversão e à salvação de Israel.

Todavia, esta visão também não resolveu, cabalmente, todos os problemas com relação à origem do yôm YHWH, visto que são dirigidas neste dia, da mesma forma, maldições contra Israel e a idéia da «guerra santa» não está presente em todas as alusões textuais onde aparece o yôm $\mathrm{YHWH}^{42}$.

\subsection{Outras tentativas de solução}

A partir destas três hipóteses, encontra-se o parecer de outros críticos que, favoráveis ou não a elas, desenvolveram as suas próprias hipóteses que, a bem dizer, poderiam ser chamadas e consideradas como de hipóteses complementares.

L. Cerny ${ }^{43}$ é contrário à posição de Mowinckel, não obstante aceite a existência da festa de entronização de YHWH. Este autor sustenta que a origem do yôm YHWH não deve ser relacionada à festa de entronização de YHWH (logo, ao culto), mas à idéia de que YHWH, como os deuses do panteão assiro-babilônico, é quem determina e decreta o destino dos homens.

No calendário assiro-babilônico existiam dias particulares de fortuna e de infortúnios que já estariam previstos e decretados pelos deuses. A expressão yôm YHWH, usada pelos profetas, teria na sua base uma tradição popular local, que sofreu o influxo da literatura dos povos circunvizinhos.

$\mathrm{Na}$ opinião de Cerny, a antiga concepção do yôm YHWH está dominada pela idéia de que somente YHWH pode determinar o destino de algo ou de alguém, tornando-se, assim, um dia onde YHWH seria o único capaz de decretar o desfecho da história e dos homens. Com isto recupera, de certo modo, a visão escatológica que este dia representa na concepção profética.

\footnotetext{
${ }^{41}$ E. JENNI segue este parecer ("םיו"י,, in E. JENNI - C. WESTERMANN, Diccionario Teologico Manual del Antiguo Testamento, I, 998-1000), mas aceita Am 5,18-20 como a referência mais antiga, afirmando ainda que no yôm YHWH existe um caráter ambivalente, pois é um dia que traz desgraça para os inimigos de YHWH e salvação para os seus fiéis. Tudo depende do lado em que esteja Israel ou os reais destinatários da profecia.

${ }^{42}$ Cf. F. C. FENSHAM, "A Possible Origin of the Concept of the Day of the Lord”, 90.

${ }^{43}$ Cf. L. CERNY, The Day of Yahweh and Some Relevant Problems, Prague 1948, 44.78-84.
} 
A. Kapelrud, nesta mesma ótica e considerando válido o ponto de partida de Cerny ${ }^{44}$, afirma que estes dias particulares, nos quais as divindades determinavam o destino dos homens, ocorriam predominantemente no decorrer de uma festa cultual, porque tal determinação é de fato um ato cultual. Só o alto escalão divino poderia executar tal tarefa e isso dentro de uma solene ocasião, como num ato cúltico. Kapelrud aproxima-se da posição de Mowinckel, sem contudo deixar de valorizar a crítica levantada por Cerny ${ }^{45}$.

J. Héléwa, com uma outra perspectiva e não aceitando como suficientes as conclusões de G. von Rad, pensa que tais conclusões podem ser enriquecidas se forem colocadas e relacionadas em perspectiva da aliança de YHWH com o povo eleito ${ }^{46}$. Para Héléwa, o binômio maldição-bênção, ligado à aliança, é um elemento tradicional indispensável a ser considerado, caso se deseje proporcionar e se obter uma justa compreensão sobre o yôm YHWH.

Todavia, diante desta hipótese, A. Spreafico afirma que tal expressão aparece como uma fórmula fixa, não devendo ser usada como paralela a outros textos, onde temos o yôm seguido de outras especificações ${ }^{47}$.

Spreafico argumenta ainda, de maneira convincente, que não são poucas as dificuldades, pois em nenhum dos textos que aludem ao yôm YHWH existe uma referência clara e explícita à aliança, às suas fórmulas ou ao seu esquema. $\mathrm{O}$ binômio maldição-bênção é um dado recente no AT, pois pertence à teologia deuteronomista ${ }^{48}$.

F. C. Fensham, admite que a busca por uma solução, quanto à origem do yôm YHWH, não é uma tarefa fácil para os exegetas, devido às dificuldades que existem para se localizar com precisão o seu Sitz im leben e o desenvolvimento que esta expressão apresenta na literatura bíblico-profética.

Segundo Fensham, o único modo aberto e viável para a investigação progredir é fazer um estudo mapeando a situação gramatical na qual esta expressão é usada e onde ela se apresenta numa cadeia construta ${ }^{49}$.

\footnotetext{
${ }^{44}$ Cf. A. S. KAPELRUD, The Message of the Prophet Zephaniah, 83.

${ }^{45}$ Cf. A. S. KAPELRUD, The Message of the Prophet Zephaniah, 54.

${ }^{46}$ Cf. J. HÉLÉWA, "L’Origine du Concept Prophétique du 'Jour de Yahvé'”, 3-36.

${ }^{47}$ A. Spreafico (cf. Sofonia, 98-99), apresenta tal posição para mostrar-se contrário a G. von Rad, que utiliza Is 34,8 (dia de vingança para YHWH); Jr 46,10 (dia de vingança) e Ez 7,7 (o dia está próximo) como textos chaves para explicar a concepção subtendida ao yôm YHWH.

${ }^{48}$ Cf. A. SPREAFICO, Sofonia, 102. Todavia, questionando a posição de Spreafico, poderíamos perguntar: não seria possível pensar numa evolução da expressão ou no seu uso numa perspectiva da aliança, revelando-se como um progresso do pensamento teológico em Israel capaz de conjugar tradições diferentes?

${ }^{49}$ F. C. FENSHAM ("A Possible Origin of the Concept of the Day of the Lord", 91) sustenta, igualmente, que seria lucrativo estudar outros conceitos que aparecem usados em conexão imediata com o termo YHWH em estado construto.
} 
Um estudo desta natureza apresenta como resultado dois elementos coanexos: por detrás do yôm YHWH está uma devastadora força dirigida contra a infidelidade de Israel, mas também uma portentosa ação divina contra os seus inimigos estrangeiros: Babilônia, Egito, Edom e várias nações hostis ${ }^{50}$.

Diante da sua conclusão, questiona a hipótese de G. von Rad, pois se a origem do yôm YHWH fosse a "guerra santa» a favor de Israel, como se interpretaria um tal efeito destrutivo também existente e aplicável a Israel?

Para Fensham, o yôm YHWH deveria ser visto como uma vinda de Deus (teofania) para executar as maldições prescritas (através de uma guerra ou não) contra os que praticaram a injustiça ou transgrediram a aliança. É um dia particular da ação de YHWH, só por Ele determinado e fixado, cuja presença poderia significar bênção e salvação ou julgamento e castigo, uma vez que estes parecem predominar nos oráculos proféticos ${ }^{51}$.

A infidelidade de Israel é apresentada pelos profetas como digna de castigo, no mesmo sentido em que se aplica uma punição aos seus inimigos. Diante desta postura, o yôm YHWH não pode ser considerado e entendido como sendo só um dia de bênção e salvação alcançado pela «guerra santa» (sem desprezar totalmente a hipótese de G. von Rad), mas é, igualmente, um dia de julgamento e castigo. Neste dia, os povos inimigos de Israel receberão a paga por suas más ações na forma de maldições executadas, ao passo que Israel receberá o julgamento como resultado da sua infidelidade à aliança. Fensham aproxima-se desta forma à posição de J. Héléwa ${ }^{52}$.

Embora a ação devastadora, por meio de uma guerra, fosse uma das formas de se executar uma maldição ou castigo - uma das muitas penas que podiam ser aplicadas ao transgressor de um pacto - não era a única, pois o castigo divino podia acontecer por meio de fenômenos ocorridos na natureza, que na sua base não são partes integrantes do conceito de «guerra santa».

Neste sentido, reconsidera-se o texto de Am 5,18-20 como sendo o ponto de partida para o início de uma elaboração explícita da idéia que se seguirá do yôm YHWH. Este parecer é considerado relevante, ainda que os elementos da «guerra santa» não sejam constitutivos da expressão. No caso de

\footnotetext{
${ }^{50}$ Contra Israel: Is 2,12; 22,5; Ez 7,19; 13,5; J1 1,15; 2,1.11; 3,4; 4,14; Am 5,18-20; Sf 1,7-8.14-18; contra Babilônia: Is 13,6.9-13; contra o Egito: Jr 46,10; Ez 30,3; contra Edom: Is 34,8; Ab 15. Para uma posição contrária sobre o sentido e interpretação dos textos em Joel, veja-se L. A. FERNANDES., $O$ yôm $Y H W H$ em $\mathrm{Jl}$ 2,1-11.

${ }^{51}$ Cf. F. C. FENSHAM, "A Possible Origin of the Concept of the Day of the Lord", 91-92.

${ }^{52}$ Cf. A. J. EVERSON, "The Days of YAHWEH", 330. O yôm YHWH poderia ser um dia de visitação da parte de Deus para punir os pecados e a conduta infiel de Israel por meio de uma guerra na qual serão executadas maldições contra a deslealdade. $\mathrm{O}$ instrumento desta guerra pode ser a investida de uma nação estrangeira contra Israel, como a Assíria ou Babilônia.
} 
Amós, também se aplicaria um castigo contra as nações estrangeiras e contra o Israel infiel pelos fenômenos cósmicos que se desencadeiam na natureza ${ }^{53}$.

Assim, as conclusões a que chega Fensham são relevantes:

a) a infidelidade de Israel é colocada pelos profetas como digna de castigo por meio de maldições, que entram em vigor no momento em que o povo rompe o pacto;

b) em alguns casos, a «guerra santa» pode também ser empreendida contra Israel por sua infidelidade;

c) em outros casos, o dia de castigo contra os infiéis entrará em ação por meio de fenômenos sobrenaturais e calamidades naturais;

d) o yôm YHWH não pode ser considerado como proveniente somente da «guerra santa», pois seria uma das formas de se aplicar uma maldição ao transgressor;

e) o fundo real do yôm YHWH é ser um dia de visitação da parte de YHWH para executar o seu julgamento por meio de maldições ${ }^{54}$.

Enfim, Y. Hoffmann ${ }^{55}$, retomando de certa forma as hipóteses de Gressmann e Mowinckel, no tocante à escatologia, afirma que o estudo da expressão yôm YHWH é inseparável da questão que envolve a escatologia veterotestamentária. O yôm YHWH vai considerado como uma expressão que se desenvolveu e sofreu uma metamorfose, assumindo características próprias, até se tornar um termo técnico para indicar uma particular teofania de YHWH (aproxima-se da hipótese de Héléwa).

No tempo de Amós, o yôm YHWH ainda não era um conceito claro e totalmente definido, mas adquiriu um caráter e uma especificação da linguagem bem definidos como conseqüência da profecia de Sofonias. Nela, o yôm YHWH assume um tom e colorido escatológico, pelo fato de que aquilo que ocorrerá neste dia é anunciado com as características de um acontecimento universal e definitivo para Israel e os outros povos envolvidos ${ }^{56}$.

Amós concentrou-se em afirmar que YHWH se manifestará não como pensado e esperado na sua época, de modo a usar a expressão yôm YHWH num sentido teofânico, com conseqüências desastrosas, e assim a expressão foi usada ou reinterpretada nos demais textos proféticos ${ }^{57}$.

\footnotetext{
${ }^{53}$ Cf. F. C. FENSHAM, "A Possible Origin of the Concept of the Day of the Lord”, 93-95.

${ }^{54}$ Cf. F. C. FENSHAM, "A Possible Origin of the Concept of the Day of the Lord", 95-96.

${ }^{55}$ Cf. Y. HOFFMANN, "The Day of the Lord as Concept and a Term in Prophetic Literature", 37-50.

${ }^{56}$ Cf. C. CARNITI, "L'espressione 'il Giorno di Yhwh'...”, 19; Y. HOFFMANN, “The Day of the Lord as Concept and a Term in Prophetic Literature", 46; A. SPREAFICO, Sofonia, 104.

${ }^{57}$ Cf. C. VAN LEEUWEN, "The Prophecy of the Yôm YHWH in Am V,18-20", OTS 19 (1974) 113-134.
} 
Hoffmann afirma que a ligação entre a «guerra santa» e o yôm YHWH não é essencial, porque a «guerra santa» é um elemento teofânico comum. É essencial, porém, no yôm YHWH a teofania, porque é esperado como o dia em que YHWH se manifestará especificamente para julgar e esta sua manifestação será portadora de salvação para os que são fiéis e/ou de condenação para os inimigos do seu povo.

Este dia está acompanhado, como nas teofanias, de uma série de fenômenos cósmicos que envolvem a natureza e a humanidade, e são descritos como conseqüências do yôm YHWH (cf. Ez 30,4; Is 13,7-8; J1 3,4; 4,15), servindo para indicar a própria manifestação divina deste dia ${ }^{58}$.

A expressão se torna compreensível e clara no conjunto dos oráculos proféticos como sendo um modo para anunciar uma portentosa intervenção de YHWH, assumindo características típicas e próprias da teofania. Deve-se, desta forma, perceber que o yôm YHWH constitui uma importante ligação entre o anúncio profético de salvação e de desgraça, isto é, possui um caráter ambivalente no que diz respeito às suas conseqüências para Israel.

Em si mesmo, considerando a maioria dos textos proféticos, o caráter do yôm YHWH é funesto, pois possui um valor negativo. Contudo, ele não deixará de produzir salvação, pois a punição aplicada a alguns (nações inimigas) pode-se manifestar vantajosa em relação a outros (Israel ou o resto que permaneceu fiel). Mostra-se, assim, a unidade interna e o valor escatológico do anúncio profético em forma de oráculos de desgraça e salvação ${ }^{59}$.

Concluindo este pondo, vê-se que por detrás das hipóteses apresentadas já podemos colher alguns elementos centrais. O yôm YHWH tem a ver com a escatologia e com a justiça divina que se manifesta quer pela teofania, quer pelo culto, quer por meio de uma ação bélica. A clareza que buscamos ter a respeito deste dia passa, agora, pela avaliação texto a texto, a fim de se poder emitir um juízo mais completo sobre esta temática.

\section{O yôm YHWH no corpus dos Doze Profetas}

Nos últimos trinta anos, surgiram vários trabalhos com relação ao Dodekapropheton $^{60}$. Considera-se uma prática fascinante ler os doze profetas

\footnotetext{
${ }^{58}$ Sobretudo com o yôm no estado construto ou quando é seguido de um ou mais predicados: cf. Ez 30,3; Am 5,18.20; Jl 2,2 e Sf 1,14-16.

${ }^{59}$ Cf. Y. HOFFMANN, "The Day of the Lord as Concept", 50; "שיוי", in E. JENNI - C. WESTERMANN, Diccionario Teologico Manual del Antiguo Testamento, I, 1000; A. SPREAFICO, Sofonia, 102-105.

${ }^{60}$ P. R. HOUSE, "The Unity of the Twelve", Sheffield, 1990; P. L. REDDITT, "The Production and Reading of the Book of the Twelve", Atlanta, 1997, 394-419; R. RENDTORFF, "How to Read the Book of the Twelve as a Theological Unity", Atlanta, 1997, 420-432; J. D.
} 
como uma unidade canônica, sem deixar de levar em conta que tal unidade está obviamente composta de partes e elementos muito diferentes e divergentes. ${ }^{61}$

É interessante, para este tipo de estudo, o fato de que Eclo 49,10 teça um elogio aos doze profetas, dizendo que eles consolaram e resgataram Jacó na fé e na esperança, levando a crer que no séc. II a.C. eles já eram considerados como um corpus. Poder-se-ia perguntar: sobre quem Ben Sirac estaria se referindo ao mencionar os doze profetas? É difícil dizê-lo, pois Oséias, Amós, Miquéias e os outros, profetizaram muito mais sobre desastres e castigos divinos que, propriamente e sem excluir, sobre esperança e salvação.

Todavia, não estaria aí, exatamente, a grande contribuição que deram estes profetas, justamente no momento em que vaticinam desgraças? Isto não levaria o povo a se recordar de sua origem, buscando se converter e cumprir suas obrigações para com YHWH? Esta não é a visão que apresenta a forma final de cada um dos doze profetas, ao incluírem oráculos salvíficos ao lado de oráculos de julgamento ou anúncios de desgraças?

Não é possível ignorar o fato de que a complexidade que gira em torno do conjunto deste corpus profético é extremamente delicada, porque permanece difícil controlar as expressões tidas muitas vezes como contraditórias nesta coleção de oráculos. O estudo sobre a unidade deste corpus ainda não se firmou como provável, mas alguns críticos acreditam que um bom caminho nesta direção seria seguir as trilhas deixadas pelo uso de certas palavras consideradas chaves ${ }^{62}$ e que poderiam servir de elemento organizador para a sua composição como um todo, ou pelo menos, para algumas partes

NOGALSKI, em seu artigo sobre o yôm YHWH no Livro dos Doze, apresenta um investigação sobre este tema ao mesmo tempo em que analisa, brevemente, algumas expressões consideradas conexas ao yôm YHWH (cf. J. D. NOGALSKI, "The Day(s) of YHWH in the Book of the Twelve", Atlanta, 1999, 617-642). Para uma ampla e atualizada bibliografia, veja-se o site http://www.uni-essen.de/Ev-Theologie/twelve/12b_bib1-date.htm.

${ }^{61}$ Nenhum método crítico, por mais completo que pretenda ser, consegue resolver todas as questões hermenêuticas. Assim, o documento da Pontifícia Comissão Bíblica afirma que: "A respeito da inclusão no método, de uma análise sincrônica dos textos, deve-se reconhecer que se trata de uma operação legítima, pois é o texto em seu estado final, e não uma redação anterior, que é expressão da Palavra de Deus. Mas o estudo diacrônico continua indispensável para o discernimento do dinamismo histórico que anima a Sagrada Escritura e para manifestar sua rica complexidade... Em definitivo, o objetivo do método histórico-crítico é de colocar em evidência, de maneira sobretudo diacrônica, o sentido expresso pelos autores e redatores. Com a ajuda de outros métodos e abordagens, ele abre ao leitor moderno o acesso ao significado do texto da Bíblia, tal como o temos" [Pontifícia Comissão Bíblica, A Interpretação da Bíblia na Igreja, I, A, 4 (cf. EB 1289)].

62 Por exemplo as duas obras de J. D. NOGALSKI, Literary Precursors to the Book of the Twelve, Berlin, 1993 e Redactional Processes in the Book of the Twelve, Berlin, 1993. 
que revelam uma certa intencionalidade redacional no âmbito profético. Um tema específico que aparece notado no Dodekapropheton é o yôm $\mathrm{YHWH}^{63}$.

J. D. Nogalski afirma, sem exemplificar, que a intervenção divina pelo yôm YHWH desenvolve um quadro de múltiplas qualidades, que incluem cinco pontos: o tipo de ação, o destinatário, a razão, o tempo da intervenção e as possiveis conexões literárias.

a) Quanto à ação, ela pode ser positiva ou negativa. Será positiva quando se apresenta uma possibilidade de retratação da parte do povo para com YHWH, resultando em salvação, libertação ou restauração. Será negativa quando envolve, essencialmente, um julgamento que acarretará a aniquilação parcial ou total dos imputados. Será parcial quando, aplicado um julgamento, se obtém uma purificação, deixando a salvo um resto, que permanece devido uma mudança de comportamento, como no caso da conversão e do retorno de todo coração para YHWH.

b) Quanto aos destinatários da intervenção, estes podem ser tanto o povo eleito como as nações estrangeiras ou ambos conjuntamente, podendo variar de acordo com as razões específicas que levam YHWH agir contra ou a favor do seu povo ou das nações.

c) Quanto às razões, na maioria das vezes, podem-se referir às transgressões não toleradas por YHWH, que envolvem atividades culturais, éticas, religiosas ou militares.

d) Quanto ao tempo da intervenção, pode-se ter uma referência passada que serve de ilustração, a fim de conter novas razões capazes de atrair um novo castigo divino ou servem, simplesmente, para lembrar a bênção de YHWH. No que diz respeito ao aspecto futuro, este poderá ser próximo ou distante.

e) Por fim, quanto às possíveis conexões com outros textos, é necessário proceder com uma apurada reflexão, visto que a forma e o contexto das perícopes em questão podem influenciar o modo de interpretá-las. Uma citação pode fazer alusão a outra, um horizonte literário pode estar sendo desenvolvido em diferentes momentos, de modo que a linguagem ou eventos narrados podem reaparecer em textos com contextos diferentes.

Para Nogalski, avaliando-se corretamente estas características, poderse-ia determinar com mais clareza como funciona e se comporta o yôm YHWH no Dodekapropheton. Comparando-se os textos (intertextualidade), se estaria diante de uma transmissão comum, ou ao menos ter-se-ia uma orientação partilhada por parte do(s) redator(es) desses doze escritos ${ }^{64}$.

${ }^{63}$ Cf. J. D. NOGALSKI, "The Day(s) of YHWH in the Book of the Twelve", 612.

${ }^{64}$ J. D. NOGALSKI, "The Day(s) of YHWH in the Book of the Twelve", 621-622. 


\subsection{A lógica do yôm YHWH em Amós}

Am 5,18-20 não oferece elementos suficientes para se emitir um parecer claro sobre o yôm YHWH ou que possam definir a sua relevância temática para o $\mathrm{AT}^{65}$. Amós, contudo, reconheceu e anunciou que YHWH, através deste dia, manifestaria um juízo punitivo para os seus interlocutores.

A razão deste juízo encontra-se em Am 2,6-16, onde vários níveis de delitos sociais revelam os culpados em Israel que burlam o direito dos indefesos (cf. Am 2,6-8; 8,4-8) ${ }^{66}$, ignorando os feitos memoráveis de YHWH (cf. Am 2,9-12). A decisão de punir é pessoal de YHWH ('ānōk̂, v. 13). A punição virá e acontecerá através de uma ação bélica contra os que são julgados culpados (cf. Am 2,13-16).

Em Amós, a punição do ímpio ou a possível salvação dos justos é uma ação de YHWH que acontece desde Sião-Jerusalém e se impõe para todos os povos quando a lei moral é transgredida por crimes e atos desumanos (cf. Am 1,2.3-2,5), mas aquilo que se faz ao pobre, justo e indefeso, se torna critério e objeto da justiça divina no seu tribunal (cf. Am 5,12.15.24) ${ }^{67}$.

Os crimes cometidos na área social, jurídica e cultual são injustiças que vigoram em Israel (cf. Am 3,9-11.13-15; 4,1-5). Elas atraem carestias e mesmo assim não há conversão (cf. Am 4,6-12). Litígio e prelúdios de punição envolvem o anúncio que Amós faz do yôm YHWH (cf. Am 3,2; 4,12; 5,1-17). Como os líderes «odeiam» (שָׁניאוּ) a correção dos justos (cf. Am 5,10-13),

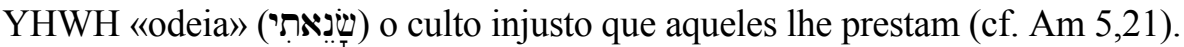

As perguntas em Am 5,18-20 soam como retórico-polêmicas e dão a saber que os desejosos ${ }^{68}$ pela manifestação do yôm YHWH buscavam sua

\footnotetext{
${ }^{65}$ Cf. G. von RAD, «The Origin», 98-99; The Message of the Prophets, 95; N. WENDEBOURG, Der Tag des Herrn: Zur Gerichtserwartung im Neuen Testament auf ihrem alttestamentlichen und frühjüdischen Hintergrund, Neukirchener-Verlag 2003, 31; P. G. SCHWESIG, Die Rolle, 6-19.

${ }^{66}$ Para A. Spreafico («Padre degli orfani, difensore delle vedove [Sal 68,8]: Dio padre di giustizia», Euntes Docete 52 [1999] 274-275), esta atitude contraria o princípio do mišsāt no confronto com os pobres (cf. Am 5,11-12; Dt 25,1; Is 10,1-5).

${ }^{67}$ Cf. H. REIMER, "Amós - profeta de juízo e justiça" RIBLA 35/36 (2000), 175-177; A. SPREAFICO, "Amos: il povero come giusto in un contesto di ingiustizia", RSB 1-2 (2002) 48-52.

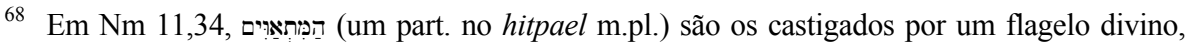
porque se deixaram levar pelo desejo exagerado. K. D. Mulzac ("Amos 5:18-20 in its Exegetical and Theological Context", AJTh 16/2 [2002] 290-291) identifica הַמְּרָאוּים como sendo os citados em Am 5,7.11, isto é, os injustos sociais e transgressores da aliança. Assim, também, J. R. WOOD, Amos in Song and Book Culture, JSOTS 337, Sheffield 2002, 129.
} 
vinda como uma solução cultual, mas ignoravam a gravidade do que estavam pedindo ${ }^{69}$.

Se, por um lado, a administração de Jeroboão II gerou a idéia equivocada sobre o sentido da bênção no âmbito da retribuição divina (cf. Dt 27-30) ${ }^{70}$; o yôm YHWH, por outro lado, é a compreensão de um profeta oriundo do Sul (cf. Am 1,2) que denuncia o erro de se pensar a salvação como triunfo temporal ligado a uma época de prosperidade material ${ }^{71}$.

O oráculo iniciado com הוֹ 1 (Am 5,18) revela que morte, luto e lamento resultam da ação reservada para este dia, porque YHWH reprova e não pactua com os planos humanos injustos (cf. Am 6,3; 9,5).

Se a injustiça em que vivem os seus interlocutores tornou-se a razão para Amós denunciá-la em tom de severa reprovação, então, a situação de pecado condiz com a natureza tenebrosa que recairá sobre eles no yôm $\mathrm{YHWH}$ (cf. Am 4,3; 5,8). A ironia das metáforas - leão, urso e serpente - confirma que não se escapará da justiça divina que este dia acarretará (cf. Am 5,19) ${ }^{72}$.

Amós não está combatendo a mentalidade do povo em geral ou dos pobres em particular, mas a idéia daqueles que se escondiam atrás de uma verdade: o yôm YHWH é um triunfo e vingança sobre os inimigos ${ }^{73}$. Para Amós, pior que a ameaça inimiga externa é a ameaça inimiga interna, onde se pervertem os canais da promoção do direito e da justiça, fazendo da monarquia e do sacerdócio os associados na prática da iniqüidade (cf. Am 7,9.11.13).

Amós valida a aplicação do yôm YHWH não só como um juízo punitivo para as nações estrangeiras, mas contra a elite do reino do Norte capaz de manipular a política, a justiça, o culto e a visão de Deus, pondo em risco o futuro da inteira comunidade ${ }^{74}$. Falando aos grandes do povo, o profeta não só alertava ou ameaçava, mas estava buscando provocar a sua conversão, a fim

\footnotetext{
${ }^{69}$ Cf. C. van LEEUWEN, "The Prophecy of the Yôm YHWH in Amos V 18-20", in J. BARR et al, ed., Language and Meaning: Studies in Hebrew Language and Biblical Exegesis, Leiden 1974, 117; H. SIMIAN-YOFRE, Amos, Milano 2002, 123. Segundo A. J. EVERSON (cf. The Day of Yahweh, 123-129) é a distorção da eleição e proteção divinas.

${ }^{70}$ Cf. G. FOHRER, "Der Tag Jhwhs", 43; H. SIMIAN-YOFRE, Amos, 13-27; A. S. KAPELRUD, The Message, 81; S. HERRMANN, Time and History, Nashville 1981, 132-133; J. A. SOGGIN, Il Profeta Amos, Brescia 1982, 130; A. GELIN, «Jours de Yahvé», 44.

${ }^{71}$ Cf. H. SIMIAN-YOFRE, Amos, 33; E. FRADES, "El Rostro de Dios Según Amos", ITER (1999) 141-144; H. SWANSTON, “Joel”, in L. BRIGHT, ed., Prophets II, Chicago 1972, 73-76.

${ }^{72}$ Cf. R. ALBERTZ, Historia de la religión de Israel en tiempos del Antiguo Testamento, I-II, Madrid 1999, 309-313; H. SIMIAN-YOFRE, Amos, 121.

${ }^{73} \mathrm{O}$ yôm $\mathrm{YHWH}$, embora se ligue exclusivamente à pregação dos profetas do reino do Sul, é um evento comum e esperado pelos dois reinos (cf. M. SÆBØ, «םיוי), ThWAT, III, 583).

${ }^{74}$ Cf. H. SIMIAN-YOFRE, Amós, 124.
} 
de salvar os pequenos de um sofrimento ainda maior, que os levaria a padecer com o castigo cabido como punição para os culpados ${ }^{75}$.

Com a mensagem da chegada do dia de trevas, Amós entende motivar a sentença que porá fim à falsa pretensão material e abrirá a via de esperança. Este passo reduz ao vazio um futuro marcado de engano e denota que é preciso eliminar o equívoco de um progresso régio gerador de injustiças. É um falso shalôm que se entrevê, que surgirá como dúvida no anúncio bélico de Jr 4,5-31 (cf. Jr 4,10) e como forte denúncia no contexto de Ez 13,2-16.

Na compreensão de Amós, o yôm YHWH é uma ocasião que restabelecerá a justiça e o direito, que deveriam ser à base das atitudes do monarca $\mathrm{e}$ dos que no culto buscavam os favores divinos. Este dia, revelando a potência de YHWH, produzirá não a libertação do inimigo, mas purificará a liturgia. $\mathrm{O}$ resultado obtido por meio desta ação divina será o shalôm capaz de manter o povo eleito na fidelidade ${ }^{76}$.

A concepção do yôm YHWH como anúncio de punição em Amós não contradiz o sentido salvífico que este dia representa. YHWH, castigando os injustos, externos ou internos a Israel, revela que não é indiferente ao seu comportamento. YHWH, agindo desta forma, livra os justos dos ímpios, não deixando que estes continuem maltratando aqueles (cf. Sl 125,3).

O yôm YHWH em Amós é um juízo que se apresenta com uma face negativa e positiva. Do contrário, não faria sentido o anúncio deste dia continuar sendo uma forma para se evitar a queda de Jerusalém e o exílio pela ação profética de Sofonias e Jeremias (cf. Sf 1,7.14-18; Jr 4,5-31), um modo de sustentar os deportados com Ezequiel (cf. Ez 2,3-5; 13,2-16) e uma esperança com Isaías (cf. Is 2,12-17; 13,2-16).

O que decorrerá com a vinda do yôm YHWH mostrará a natureza dos laços que existem entre a iniciativa divina de punir e a liberdade humana das ações que provocaram esta punição ${ }^{77}$. Todavia, o interesse salvífico de YHWH continua sendo um dom oferecido ao seu povo, porque Ele é fiel à sua escolha e porque o constituiu mediador para os outros povos.

\footnotetext{
${ }^{75}$ Esta preocupação reaparece na exortação contida em Sf 2,1-3.

${ }^{76}$ Cf. H. SIMIAN-YOFRE, Amos, 123-124; J. P. COMISKEY, «The Day of Yahweh», 2217; H. REIMER, «Amós», 188-190.

77 J. L. Barriocanal Gómez (La Relectura de la Tradición, 142-144) admite que Am 5,18-20; Jl 3-4 e Ml 3 são um passo na reflexão teológico-espiritual do yôm YHWH, pois ele não é percebido só como juízo punitivo, mas também como juízo salvífico. Com isso, Jl 1-2 é uma reflexão explícita do yôm YHWH como impulso de conversão.
} 


\begin{abstract}
This paper, that's presented in two parts, contemplates the status quaestionis about the thematic of the yôm YHWH. It considers the importance of this expression for the prophetical eschatology in the Old Testament, and it presents a cohesion of the yôm YHWH in the corpus of the Dodekapropheton. The article suggests a new interpretation about this thematic in the book of Joel. It will help the comprehension of other books that have this expression in this corpus.
\end{abstract}

Leonardo Agostini Fernandes

Doutor em Teologia pela PUG-Roma

Professor do Departamento de Teologia da PUC-RJ 